Doniach, D., Roitt, I. M., Walker, J. G., and Sherlock, S. (1966). Clin. exp. Immunol., $1,237$.

Feizi, T. (1968). Gut, 9, 193.

Fischer, J. A., and Schmid, $M$. (1967). Lancet, 1, 421. Fox, R. A., Sherlock, S., Scheuer, P. J., Sharma, O., and James, D. G.

Gajdusek, D. C. (1958). Arch. intern. Med., 101, 9.

Gallo, D. G. Bailey, K. R., and Sheffner, A. L. (1965). Proc. Soc. exp. Biol. (N.Y.) 120,60 .

Gökcen, M. (1962). 3. Lab. clin. Med., 59, 533.

Goudie, R. B., Macsween, R. N. M., and Goldberg, D. M. (1966). J. clin. Path., 19, 527.

Hobbs, J. R. (1966). Proc. roy. Soc. Med., 59, 568.

Hobbs, J. R. (1966). Proc. roy. Soc. Med., 59, 568 .

Hollander, M., and Schaffner, F. (1968). Amer. J. Dis. Child. In press.

Javitt, N. B. (1966). Gastroenterology, 50, 394.

Kehayoglou, A. K., Holdsworth, C. D., Agnew, J. E., Whelton, M. J., and Sherlock, S. (1968a). Lancet, 1, 715 .

Kehayoglou, A. K., Williams, H. S., Whimster, W. F., and Holdsworth, C. D. (1968b). Gut. In press.

Kreek, M. J., Sleisenger, M. H., and Jeffries, G. H. (1967). Amer. F. Med., 43, 795.

Levine, R. A., Briggs, G. W., and Lowell, D. M. (1966). Gastroentero$\log y, 50,665$.

Linscheer, W. G., Patterson, J. F., Moore, E. W., Clermont, R. J., Robins, S. J., and Chalmers, T."C. (1966). f. clin. Invest., 45, 1317. Mistilis, S. P., Skyring, A. P., and Goulston, S. J. M. (1965). Aust. Ann. Med., 14, 286.

Morgan, D. B., Paterson, C. R., Woods, C. G., Pulvertaft, C. N., and Fourman, P. (1965). Lancet, 2, 1085 .

Mulligan, R., and Sherlock, S. (1968). Unpublished.

Myers, J. D., Olson, R. E., Lewris, J. H., and Moran, T. J. (1957). Trans. Ass. Amer. Phycns, 70, 243.

Okuyama, K. (1965). Y. Pediat., 67, 89.
Osborn, E. C., Wootton, I. D. P., da Silva, L. C., and Sherlock, S. (1959). Lancet, 2, 1049 .

Palmer, R. H., and Hruban, Z. (1966). 7. clin. Invest., 45, 1255

Paronetto, F., Schaffner, F., and Popper, H. (1964). New Engl. ł. Med., 271, 1123 .

Rankin, J. G., Skyring, A. P., and Goulston, S. J. M. (1966). Gut, 7, 433.

Read, A. E., Harrison, C. V., and Sherlock, S. (1961). Amer. J. Med., $31,249$.

Rose, G. A. (1967). In Scientific Basis of Medicine Annual Review, p. 257. London.

Rubin, E., Schaffner, F., and Popper, H. (1965). Amer. Y. Path., 46, 387. Saunders, D. R., and Ḋawson, A. M. (1967). In Biochemical Problems of Lipids, edited by A. C. Frazer. Amsterdam.

Schoenfield, L. J., Siövall, J., and Perman, E. (1967). Nature (Lond.), 213, 93 .

Scott, A. J., and Khan, C. A. (1968). Gut, 9, 187.

Sherlock, S. (1959). Gastroenterology, 37, 574.

Sherlock, S. (1966). Ann. intern. Med., 65, 397.

Sherlock, S. (1968). Diseases of the Liver and Biliary System, thed., p. 296 . Oxford.

Smetana, H. F., Edlow, J. B., and Glunz, P. R. (1965). Arch. Path., 80, 553.

Stauffer, M. H., Sauer, W. G., Dearing, W. H., and Baggenstoss, A. H. (1965). Y. Amer. med. Ass., $191,829$.

Stowens, D. (1963). Ann. N.Y. Acad. Sci., 111, 337

Thorpe, M. E. C., Scheuer, P. J., and Sherlock, S. (1967). Gut, 8, 435.

Walker, C. O., and Combes, B. (1966). Gastroenterology, 51, 631 .

Walker, J. G., Doniach, D., Roitt, I. M., and Sherlock, S. (1965). Lancet, $1,827$.

Webling, D. D'A., and Holdsworth, E.' S. (1965). Biochem. Y., 97, 408.

Whelton, M. J., Petrelli, M., George, P., Young, W. B., and Sherlock,

Zaki, F. (1968). In pre Carey, J. B., jun., Hoffbauer, F. W., and Nwokolo, C. (1967). 7. Lab. clin. Med., 69, 737.

\title{
Thermography in Occlusive Cerebrovascular Diseases
}

\author{
C. MAWDSLEY,* M.B., M.R.C.P., M.R.C.P.ED. ; E. SAMUEL, † M.D., F.R.C.P.ED., F.R.C.S., F.R.C.S.ED., F.F.R. \\ M. D. SUMERLING $\ddagger$ M.B., M.R.C.P., M.R.C.P.ED., F.F.R. ; G. B. YOUNG, M.B., F.R.C.S.ED., F.F.R.
}

[With Special Plate facing Page 524]

Brit. med. F., 1968, 3, 521-524

\begin{abstract}
Cummary : Cooling of the skin over the medial supraorbital region in $80 \%$ of patients who have an occlusion or severe stenosis of a carotid artery can be demonstrated by facial thermography. Minor stenotic lesions in the carotid arteries do not produce characteristic thermographic changes, while thermography is of no help in the diagnosis of vertebrobasilar arterial disease.

Thermographic changes suggestive of carotid arterial lesions are found occasionally in patients whose angiograms are normal, owing to variations in the size of the frontal sinuses, or factors such as fever or inflammatory lesions.
\end{abstract}

It is suggested that facial thermography is of value in the preliminary investigation of patients with occlusive cerebrovascular cisease.

\section{Introduction}

Studies of cerebrovascular disease were, until fairly recently, concerned with the delineation of clinical syndromes caused by the occlusion of individual intracerebral arteries. Blockage of a carotid artery in the neck was reported by Cooper in 1836 and its clinical importance stressed by Hunt in 1914. Carotid arteriography (Moniz et al., 1937) provided the means of accurate diagnosis of extracranial vascular disease, and directed

* Senior Lecturer in Neurology, Edinburgh University.

t Radiologist in Charge, Department of Diagnostic Radiology, Edinburgh Royal Infirmary.

¥ Consultant Radiologist, Edinburgh Royal Infirmary. attention towards the clinical and pathological effects thereof. Hutchinson and Yates (1957) emphasized the association of disease of the carotid and vertebral arteries with cerebral lesions, and these same authors (Yates and Hutchinson, 1961) concluded that cerebral infarction was more often due to stenosis of extracranial than of intracranial arteries. Schwartz and Mitchell (1961) found that stenosis of vessels in the neck did not necessarily lead to cerebral infarction, but established a correlation between occlusion of these arteries and cerebral infarction.

The possibility of effective treatment provides a stimulus for the more precise diagnosis of extracranial lesions of the carotid and vertebral systems. Surgical treatment is helpful in some cases of atherosclerosis affecting the major vessels of the neck (De Bakey et al., 1962), while Millikan et al. (1958) have recommended the use of anticoagulants in advancing occlusion of the carotid artery and in the treatment of transient cerebral ischaemic attacks.

Marshall (1967) stressed the inaccuracy of the clinical diagnosis of cerebrovascular lesions. He pointed out that about a quarter of a million strokes occur each year in the United Kingdom and advocated careful selection, from this vast number, of those patients who need neuroradiological investigation. Angiography is probably the most useful and accurate investigation, but usually only large radiological centres are equipped to carry out this technique, and even in the most experienced hands angiography may be hazardous in patients with atherosclerosis. Lumbar puncture and echo encephalography are useful preliminary investigations in patients suffering from strokes, but their main value lies in the exclusion of intracerebral haemorrhage and tumour. Ophthalmodynamo- 
metry is helpful in the diagnosis of recent unilateral occlusion of the internal carotid artery (Liversedge and Smith, 1961). Combined with carotid compression, ophthalmodynamometry may show characteristic changes in about $90 \%$ of patients with carotid occlusion (Lowe and Stevens, 1961). However, this technique may be dangerous in the presence of local disease of the eye, notably glaucoma and retinal detachment, and requires skill and practice before reliable results are obtained. The patient's eye needs to be anaesthetized with cocaine and the pupil dilated with homatropine. Ophthalmodynamometry gives very variable results in the presence of stenosis, rather than occlusion, of the carotid artery.

Wood (1964, 1965) first demonstrated the usefulness of thermography in cerebrovascular disease. We have studied a group of patients suffering from cerebrovascular lesions, using thermographic techniques whose diagnostic value we have tried to assess.

\section{Technical Considerations}

Thermography is a refinement of thermometry. It enables very small changes in temperature to be detected. The first thermograph was designed and so named by John Herschel in 1840 ; he showed that alcohol evaporated quickly from strips of paper when these strips were exposed to the infrared radiations discovered by his father (W. Herschel, 1800).

Hardy (1939) showed that human skin is an almost perfect absorber and emitter of infrared energy between the wavelengths of 3 and 15 microns. Over this range of wavelengths skin, whatever its pigment, functions as a "black body." The temperature of an area of skin can thus reliably be determined by measuring its infrared emission. A number of detectors sensitive to infrared radiation, even at a distance, are now available, and the principles of their action are well reviewed by Gerschon-Cohen et al. (1965).

The temperature of the skin fluctuates because of such factors as skin blood flow, the rate of convection due to air currents, and the amount of insulation provided by clothing and hair. The exposed skin of the face in controlled surroundings, where the ambient temperature is kept constant and free from draughts, achieves an equilibrium with the environment. Under these conditions changes in skin temperature, and hence altered infrared emission, will reflect changes in blood flow.

The skin of the face is largely supplied by the external carotid artery. The lateral supraorbital region is supplied by the frontal branch of the superficial temporal artery, which is part of the external carotid system. The medial part of the forehead, above the inner aspect of the orbit on each side, however, is supplied by the frontal and supraorbital branches of the ophthalmic artery. The ophthalmic artery arises from the internal carotid artery just after it emerges from the cavernous sinus. A lesion of the internal carotid artery proximal to the origin of the ophthalmic artery which is sufficient to cause reduced blood flow, might be expected to lead to cooling over the central part of the forehead on the corresponding side. Lesions of the common carotid artery might cause more extensive cooling over the face on the same side, and in particular the cooling over the forehead would be likely to extend laterally. These changes in blood flow may be complicated by the opening up of some of the five anastomotic connexions between the internal and external carotid systems on the same side. After carotid occlusion the blood flow in the contralateral artery may be increased (Hardesty et al., 1961), and this might be reflected in a rise of skin temperature on the unaffected side. There are thus several possible patterns of altered facial temperature and infrared radiation which could result from carotid arterial disease. We might expect, however, that all of these changes due to proximal carotid lesions would produce some asymmetry of thermal maps of the face.

\section{Methods}

Thermal maps of patients' faces were obtained with the Aga Thermovision 652. This apparatus detects infrared radiation by means of an indium-antimonide junction cooled by liquid nitrogen. This detector converts the energy of the infrared radiation into an electrical signal. A camera unit scans the field of view at high speed, focusing the radiation on the detector, and the resulting electrical impulses are amplified and fed into an oscilloscope. The beam of the oscilloscope swings across the tube face to produce a pattern which corresponds to the scanning pattern of the camera. A picture of varying degrees of brightness corresponding to varying intensities of infrared radiation is obtained. The picture on the screen is not an infrared photograph but a mosaic pattern built up from the differing amounts of radiation from different areas of skin. The picture can be adjusted to represent varying temperature ranges from 1 to $200^{\circ} \mathrm{C}$. The instrument is sensitive enough to record difference in radiation from areas whose temperatures differ by a minimum of $0.2^{\circ} \mathrm{C}$. The picture on the oscilloscope screen is photographed with a Polaroid camera, and appears as a continuous range of grey tones. Cooler areas are represented by darker tones, so that the chin, nose, and ears and the area of skin insulated by the eyebrows appear darkest as illustrated in Fig. 1 (Special Plate).

Additional information can be obtained with this apparatus by illuminating in white, on the oscilloscope screen, those areas which are of equal temperature. This enables isothermic areas to be photographed, and thus a "contour map" may be built up so that all areas except the coolest are shown in white. This isothermic picture may be superimposed on the underlying grey thermogram (Special Plate, Figs. 2 and 6).

Patients were placed in a draught-free room of constant temperature $\left(62^{\circ} \mathrm{F} . ; 16.7^{\circ} \mathrm{C}\right.$ ) and left for 20 minutes. Thermal scans of the face in front view and in profile were then taken. The thermal maps obtained were independently examined by at least three observers, one of whom had no knowledge of the patients or the likely clinical diagnosis.

\section{Results}

A total of 125 patients were studied. Thirty-six with established cerebral infarcts causing hemiplegia or suffering from dementia due to generalized cerebrovascular disease showed normal thermographic patterns without any asymmetry. A further 17 with completed strokes, in whom a history of transient ischaemic attacks or the presence of bruits in the neck or abnormal ophthalmodynamometry suggested proximal occlusion of the carotid artery, showed asymmetrical thermograms consistent with the clinical diagnosis. In these 53 patients angiography was not carried out because of lack of clinical indication, and therefore the thermographic diagnosis could not be compared with the angiographic findings.

The remaining 72 patients were subjected to angiography or arch aortography, and it was thus possible to correlate the results of thermography with the radiological findings. $T t_{t}=$ results in this group are summarized in the Table.

\begin{tabular}{|c|c|c|c|c|}
\hline $\begin{array}{c}\text { Angiographic } \\
\text { Diagnosis }\end{array}$ & No. & $\begin{array}{l}\text { Corresponding } \\
\text { Thermogram }\end{array}$ & $\begin{array}{c}\text { Normal } \\
\text { Thermogram }\end{array}$ & $\begin{array}{l}\text { Misleuding } \\
\text { Thermogram }\end{array}$ \\
\hline $\begin{array}{lc}\text { Carotid occlusion } \\
\text { Carotid stenosis: } \\
\begin{array}{l}\text { Severe } \\
\text { Moderate }\end{array} \\
\begin{array}{ll}\text { Vertebrobasilar disease } \\
\text { Normal }\end{array} \\
\begin{array}{l}\text { Miscellaneous } \\
\text { Mis }\end{array} & \ldots \\
\end{array}$ & $\begin{array}{r}8 \\
10 \\
5 \\
6 \\
41 \\
2\end{array}$ & $\begin{array}{l}6 \\
8\end{array}$ & $\begin{array}{r}2 \\
2 \\
5 \\
3 \\
35\end{array}$ & $\begin{array}{l}3 \\
6 \\
1\end{array}$ \\
\hline
\end{tabular}

Of eight patients with a complete occlusion of the internal carotid or common carotid artery all but two showed a clearcut thermographic abnormality. The most useful and easily recognized abnormality was a cool area over the medial supra- 
orbital region. We found this sign to be consistently present when either the internal carotid or the common carotid artery was occluded. A typical example from this group is illustrated in Fig. 2 (Special Plate). Some of these patients also showed asymmetry over the cheek areas, but these changes were inconstant and difficult to interpret.

The two cases in which a complete occlusion of the internal carotid artery was associated with a normal thermogram are of interest. One was a patient in whom the occlusion was sited distally to the origin of the ophthalmic artery. The angiogram is illustrated in Fig. 3 (Special Plate), in which the ophthalmic artery can be seen filling normally; hence the normal thermogram. The other patient was a woman of 55 who presented a picture of a hemiplegia of slowly progressive nature. Angiography was carried out to exclude the presence of a tumour, and showed a complete occlusion of the internal carotid artery just distal to the bifurcation. The radiological investigation was performed at a hospital some distance away from the thermographic centre. The patient was ill and we did not think it justifiable to transport her by ambulance, so that a thermogram could not be performed until her clinical condition improved. Thus the normal thermogram was not obtained until six weeks after the demonstration of the occlusion by arteriography. Normal thermographic findings at this time suggest that the development of a collateral circulation had by then obscured the picture. Thermographic abnormalities are not always so inconstant, since in three other patients we have been able to repeat thermograms at intervals of more than a year, and in all these patients the cool area over the forehead persisted.

The patient whose thermogram is illustrated in Fig. 2 (Special Plate) is an example of persisting abnormality. He was found to have a complete occlusion of the left internal carotid artery just distal to its origin from the common carotid artery two years before the thermogram was obtained. The occlusion then was demonstrated by percutaneous angiography. Because of an increase in his symptoms arch aortography was carried out just after thermography, and this again showed a complete left internal carotid occlusion, but no lesion in any of the other cerebral arteries. Ten patients with a severe stenosis of the carotid artery were examined. In this group we included those patients whose angiographic appearance suggested an occlusion of the arterial lumen by $50 \%$ or more. Of these patients eight showed clear-cut abnormalities indistinguishable from the group with complete occlusion. Stenotic lesions in the carotid system clearly need to be sited proximal to the origin of the ophthalmic artery before a cool area over the forehead can be demonstrated. A stenosis of the intracranial part of the internal carotid artery is illustrated in Fig. 4 (Special Plate). Here there is no flow of contrast medium into the ophthalmic artery, and this is reflected in the cool area shown in the thermograms (Special Plate, Figs. 5 and 6).

Five patients with moderate or slight stenosis of the carotid artery-that is, with a lesion which occluded less than $50 \%$ of the arterial lumen-had normal thermograms.

Six patients with proved stenosis or occlusions in the vertebrobasilar system were also examined. Three of these showed normal thermographic pictures, and in three others the thermograms suggested a carotid stenosis. In the latter three patients arch aortography was performed, and no lesion was seen in the carotid arteries. In the group labelled "miscellaneous" one patient who had Takayasu's disease had an abnormal thermogram, but the area of cooling was on the side contralateral to the carotid stenosis demonstrated by arch aortography. Another patient had a large intracavernous aneurysm of the internal carotid artery, and this was accompanied by an area of increased infrared emission over the corresponding orbit.

Of 41 patients whose contrast studies were normal 35 had correspondingly normal thermograms. In six patients in whom no radiological lesion was detectable there was an area of cooling over the forehead suggesting a proximal carotid stenos1s. It is interesting that in this group of "false-positives" there were two patients in whom the clinical story strongly suggested a developing carotid lesion. Both of these patientsa man of 27 and a woman of 24-gave a history of transient ischaemic attacks culminating in a hemiplegia. The family history in both cases contained other examples of premature strokes. In each of these patients the area of cooling was on the side corresponding to the clinical findings, but the arch aortogram showed no narrowing in any of the extracranial arteries.

\section{Discussion}

The thermographic changes in this group of patients did not tally with the angiographic findings in 21 patients--that is, in nearly $30 \%$ of the total. However, in the presence of severe stenosis or complete occlusion of one carotid artery, proximal to the origin of the ophthalmic artery, there was an $82 \%$ correlation between the thermographic diagnosis and the arterial lesion demonstrated radiologically. This figure is similar to Wood's (1965) finding of $88 \%$ correspondence between thermographic and angiographic diagnosis. Aarts (1968) found the thermogram accurate in $95 \%$ of his cases. Both these authors, like ourselves, found that significant cooling of the forehead occurred when the lumen of the carotid artery was reduced by about one-half. These findings imply that blood flow in the ophthalmic artery is usually reduced in patients with carotid stenotic lesions of this severity. These changes are at variance with the experimental work of Hamilton et al. (1963) in dogs, and with the observations in humans of Brice et al. (1961). These authors found that blood flow was reduced by arterial stenosis only if the arterial lumen was reduced to a crosssectional area of 5 sq. $\mathrm{mm}$. and that significant reduction in flow did not occur until this area was reduced to $2 \mathrm{sq} . \mathrm{mm}$. These figures correspond to a reduction of the arterial lumen by a factor of 84 to $93 \%$.

It is difficult to reconcile the thermographic results of this and other studies with these experimental findings. Yates (1967) has suggested that atherosclerosis in extracranial arteries may reduce flow, not only by narrowing of the arterial channel but also by producing turbulent flow. He points out that the irregular contours of atheroma may distort the normal laminar flow in an artery, causing turbulence and giving rise to the common clinical features of a palpable thrill and audible bruit over the artery. Such a change in the flow pattern provides a possible explanation for the reduced flow in the ophthalmic artery implicit in our results.

Facial thermography is of little use in the presence of vertebrobasilar arterial disease. Thermographic findings may mislead in these circumstances by implicating the carotid arteries. A similar lack of correlation was found by Sutton and Davies (1966) in their comprehensive angiographic study. They found that only a half of the patients with symptoms of basilar insufficiency had demonstrable stenosis of any artery, and that stenoses when demonstrated were found as often in the carotid as in the vertebral systems.

Our results indicate the limitations of thermography. Misleading "false-positive" findings occur fairly commonly, and minor degrees of carotid stenosis are not revealed. The causes of inaccuracy are not always clear. We have found that some variations in the thermal pattern over the forehead correspond to variations in the size of the frontal sinuses. Pyrexia, local inflammatory lesions, bilateral disease of the carotid arteries, and stenosis of the ophthalmic artery itself are all potential sources of error. Despite these drawbacks we believe that facial thermography has a place in the investigation of cerebrovascular disease. It may be safely carried out even in ill or bed-fast patients. It causes the patients no discomfort and gives rapid results which are easily interpreted. It is a useful screening test in the selection of those patients who need angiography or aortography. 
We would like to thank Dr. W. A. Copland, who performed some of the angiograms.

\section{REFERENCES}

Aarts, N. J. M. (1968). Proceedings of 8th Symposium on Neuroradiology. In press.

Brice, J. G., Dowsett, D. J., and Lowe, R. D. (1964). Brit. med. F., 2, 1363.

Cooper, A. P. (1836). Guy's Hosp. Rep., 1, 457.

De Bakey, M. E., Crawford, E. S., Morris, G. C., and Cooley, D. A. (1962). 7. cardiovasc. Surg., 3, 12 .

Gershon-Cohen, J., Haberman-Brueschke, J. A. D., and Brueschke, E. E. (1965). Radiol. clin. N. Amer., 3, 403.

Hamilton, R. W., Holling, H. E., and Roberts, B. (1963). Surg. Forum, 14,418 .

Hardesty, W. H., Roberts, B., Toole, J. F., and Royster, H. P. (1961). Surgery, 49, 251.
Hardy, J. D. (1939) Amer. F. Physiol., 127, 454.

Herschel, J. F. W. (1840), Phil. Trans. B., 130, 52.

Herschel, W. (1800). Phil. Trans. B., 90, 225.

Hunt, J. R. (1914). Amer. F. med. Sci., 147, 704.

Hutchinson, E. C., and Yates, $P_{\dot{C}} \mathrm{O}_{\dot{H}}$ (1957), Lancet, 1, 2.

Liversedge, L. A., and Smith, V. H. (1961). Brain, 84, 274

Lowe, R. D., and Stephens, N. L. (1961). Lancet, 1, 1241.

Marshall, J (1967) Scot med $7,12,335$.

Millikan, C. H., Siekert, R. G., and Whisnant, J. P. (1958). 7. Amer. med. Ass., 166, 587 .

Moniz, E., Lima, A., and de Lacerda, R. (1937). Presse méd., 45, 977.

Schwartz, C. J., and Mitchell, J. R. A. (1961). Brit. med. F., 2, 1057.

Sutton, D., and Davies, E. R. (1966). Clin. Radiol., 17, 330.

Wood, E. H. (1964). Radiology, 83, 540.

Wood, E. H. (1965). Radiology, 85, 270.

Yates, P. O. (1967). In Modern Trends in Neurology, 4th series, edited by D. Williams. London.

Yates, P. O., and Hutchinson, E. C. (1961). Spec. Rep. Ser. med. Res. Coun. (Lond.), No. 300.

\title{
Acute Epiglottitis: Challenge of a Rarely Recognized Emergency
}

\author{
J. D. ANDREW,* M.B., CH.B., M.R.C.P.ED., D.C.H. ; O. P. TANDON, $†$ M.B., B.S., D.C.H. \\ D. C. TURK, $\ddagger$ D.M., M.R.C.P., M.C.PATH.
}

\begin{abstract}
Summary : Acute epiglottitis is a fulminating infection of young children, requiring urgent and specific treatment. Most cases are caused by infection with Haemophilus influenzae type b. Only a few cases, nearly all of them fatal, have been reported from Britain, but probably many others go unrecognized. Of four cases seen by us in the past six years three survived, having responded rapidly and completely to treatment. This consisted chiefly of measures to deal with respiratory tract obstruction and parenteral administration of antibiotics. There is need for a widespread awareness of the existence, presenting features, and extreme urgency for treatment of this disease.
\end{abstract}

\section{Introduction}

"Acute epiglottitis is a serious and often fatal condition that, although infrequently recognized, lends itself to accurate bedside diagnosis with consequent institution of specific lifesaving therapy. Its recognition and management should become familiar to all concerned with the care of sick children" (Berenberg and Kevy, 1958). This condition was clearly defined and distinguished from laryngotracheitis, diphtheritic or presumptively virus croup, and other acute respiratory tract infections by Sinclair (1941), Alexander, Ellis, and Leidy (1942), Du Bois and Aldrich (1943), Miller (1948), and Rabe (1948) on the basis of their experience in different parts of the U.S.A.; but even in that country as recently as 1958 Berenberg and Kevy had to report that only one of their 42 cases was correctly diagnosed before reaching hospital. The condition occurs mainly in children aged 2 to 7 years, but sometimes also in infants, older children, or even adults.

Characteristically, a previously healthy child develops a sore throat and increasing dyspnoea, and then within a few hours of onset becomes so severely ill that the terms " shock," " prostration," and "collapse" have been used by different authors to

\footnotetext{
* Children's Department, Bishop Auckland General Hospital, Co. Durham.

† Children's Department, Royal Victoria Infirmary, Newcastle upon Tyne. $\ddagger$ Microbiology Department, Medical School and Royal Victoria Infirmary, Newcastle upon Tyne.
}

describe the general condition. Examination of the respiratory tract shows. pharyngitis and laryngitis with supraglottic oedema, but the pathognomonic feature, which may be missed unless the tongue is depressed or pulled forward, is a swollen red epiglottis that " bears a striking resemblance to a bright red cherry obstructing the pharynx at the base of the tongue" (Berenberg and Kevy, 1958). Urgent tracheostomy or other measures to maintain an airway are usually necessary, and the infection requires prompt and adequate treatment. Chloramphenicol or ampicillin should be used for this, since it is generally accepted that the condition is due to capsulated type b strains of Haemophilus influenzae. Even Berenberg and Kevy (1958) and Vetto (1960), who suggested on rather inadequate bacteriological evidence that other bacteria are responsible for some cases, agreed that type b $H$. influenzae is the commonest cause.

The reports mentioned so far all came from the U.S.A. The British literature on this disease is scanty, but there are good reasons for believing that this is a result of its infrequent recognition rather than of its rarity. The boy reported by De Navasquez (1942) as having died in London of "acute laryngitis and septicaemia due to $H$. influenzae type $b$ " was presumably a victim of the condition that we are discussing, though the state of his epiglottis was not mentioned in the report.

No further relevant British papers appeared until Camps and Jones (Camps, 1953; Jones and Camps, 1957; Jones, 1958) described a total of 33 cases of epiglottitis seen by them in a period of 14 years. $H$. influenzae type b was incriminated in all cases in which adequate bacteriological investigation was carried out. Four patients were successfully treated, but the other 29, including the only adult, died. Jones and Camps (1957) described the fact that 26 of their first 29 cases had come to coroners' post-mortem examinations as " a challenge to the general practitioner, the paediatrician, and the laryngologist"; and a further challenge is provided by the fact that these two men who became interested in this condition were able to recognize so many cases in the course of their routine work. But these challenges have not been taken up. A few more deaths from epiglottitis have been reported in this country recently (Johnstone and Lawy, 1967; Gardner, Turk, Aherne, Bird, Holdaway, and Court, 1967; Crome, Erdohazi, and Lawson, 1968), but no more survivors. The experience of Camps 


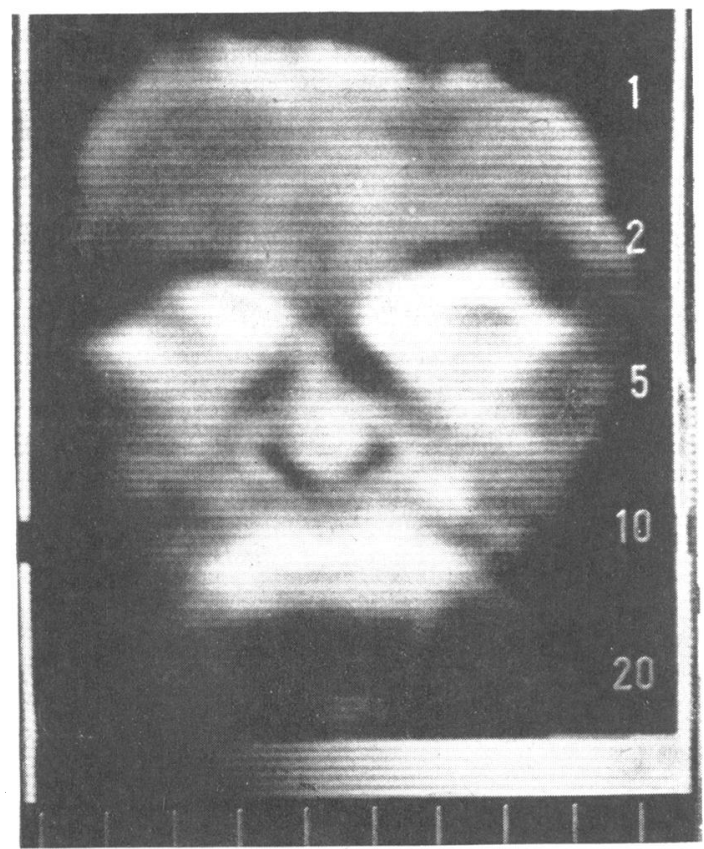

FIG. 1. - Normal heat pattern. The eyebrows and lateral aspects of the nose and chin are cold and appear black.

FIG. 4.-Left carotid angiogram showing stencarotid artery at the level of the siphon. The ophthalmic artery does not fill.
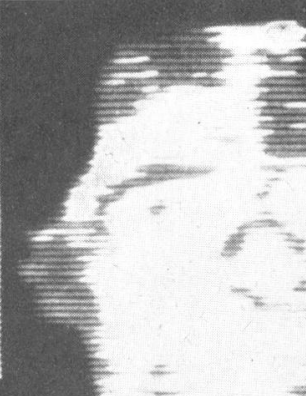

10

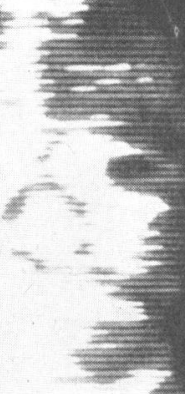

20

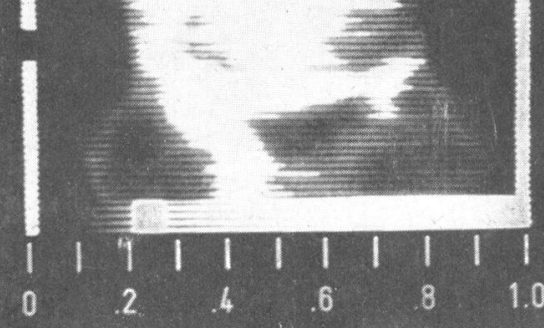

FIG. 5.-Thermogram of patient whose angiogram is shown in Fig. 4. There is a cool (dark) area over the left supra-

FIG. 2.-Left interna! carotid occlusion. Isotherm tracing superimposed on thermogram shows cold (dark) area over left side of forehead. showing a symmetrical osis of the internal orbital region.
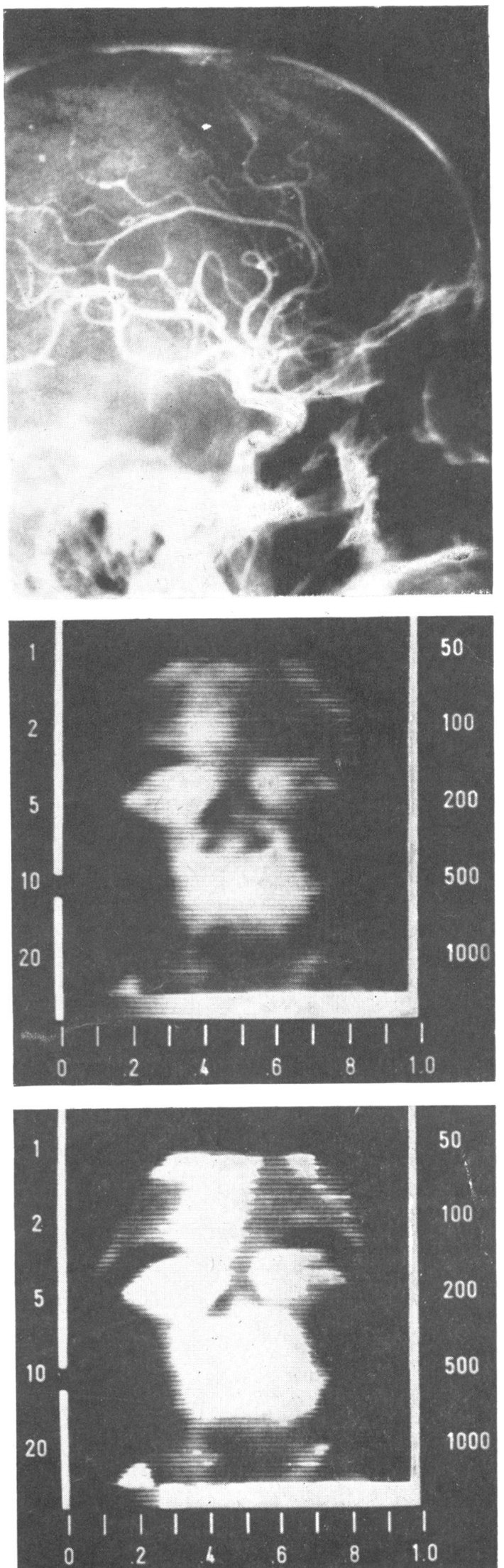

FIG. 6.-Same patient whose thermogram is shown in Fig. 5. Here the isotherm tracing is superimposed, and the cold (dark) area over the left supraorbital region is more easily seen.

Frg. 3.-Distal occlusion of left internal carotid artery. Lateral angiogram showing filling of ophthalmic artery. 